\title{
The COVID-19 Pandemic and Higher Education: Common Interdisciplinary Issues and Lessons Learned
}

\author{
Paula R. Klemm¹, Donna Ruelens-Trinkaus' ${ }^{1}$, Leslie M. Allshouse², Patricia J. Barnard1 \\ ${ }^{1}$ School of Nursing, University of Delaware, Newark, USA \\ ${ }^{2}$ Department of Medical \& Molecular Sciences, University of Delaware, Newark, USA \\ Email: klemmpa@udel.edu
}

How to cite this paper: Klemm, P.R., Ruelens-Trinkaus, D., Allshouse, L.M. and Barnard, P.J. (2020) The COVID-19 Pandemic and Higher Education: Common Interdisciplinary Issues and Lessons Learned. Open Journal of Nursing, 10, 1195-1208. https://doi.org/10.4236/ojn.2020.1012086

Received: November 17, 2020 Accepted: December 20, 2020 Published: December 23, 2020

Copyright $\odot 2020$ by author(s) and Scientific Research Publishing Inc. This work is licensed under the Creative Commons Attribution International License (CC BY 4.0).

http://creativecommons.org/licenses/by/4.0/

\begin{abstract}
Background: Coronavirus-19 (COVID-19) dramatically impacted institutions of higher education. The effect was acute in the practice disciplines such as medicine, medical laboratory science, and nursing. The purpose is to describe how an interdisciplinary team, led by nursing faculty, adapted to the changes driven by COVID-19 and the lessons that were learned for nursing and other disciplines in higher education. Method: The interdisciplinary group created a comprehensive list which captured the impact of COVID-19 on their academic disciplines. Similarities and differences between the disciplines regarding faculty experiences, teaching, and responding to student concerns were discovered. Results: Collective review resulted in the identification of four inclusive thematic categories and several sub-categories. These were: academic considerations (didactic, lab, clinical), perceptions (faculty, student), ethical considerations, and social determinants affecting the learning environment. Lessons Learned: This project utilized an innovative interdisciplinary approach to identify common COVID-19 effects on higher education. Conclusions: Nursing and other health-related disciplines should pursue interdisciplinary collaboration to address common academic issues that arise during the COVID.
\end{abstract}

\section{Keywords}

COVID-19, Higher Education, Academic Issues, Interdisciplinary

Collaboration, Lessons Learned

\section{Introduction}

Early in 2020, coronavirus-19 (COVID-19) thundered across the globe and dra- 
matically impacted all facets of society, including institutions of higher education (IHE). Consequently, educators, practitioners, and administrators sought creative solutions to ensure uninterrupted and quality education for undergraduate and graduate students. Multiple reports describe the efforts of medicine [1]-[6], dentistry [7] [8] [9], physiology [10], nursing [11] [12] [13] [14] [15], educators/administrators from institutions of higher learning [16]-[21], laboratory medicine [22] [23], physical therapy [24] [25] [26], radiology [27] [28] [29], and other healthcare specialties to provide quality education amid a global pandemic.

The impact of COVID-19 on higher education was especially acute in the practice disciplines such as dentistry, medicine, medical laboratory science, nursing, and physical therapy. Students were barred from completing clinical rotations in their practice facilities (i.e. hospitals, community centers, clinics), due to concern about their well-being. Face to face (F2F) on-campus courses were abruptly curtailed as IHEs moved to online learning management systems (LMS) (e.g. Canvas, Blackboard), and other online formats (e.g. Zoom) to provide educational content. Remote simulations were quickly developed to replace hands-on clinical experiences with patients, and students were instructed to leave campus and return home. Although multiple reports have reviewed the effects of COVID-19 on higher education and the practice professions, few if any, discussed common issues and concerns across disciplines. This singular focus is seen in the nursing literature as well [14] [30]. In short, each profession routinely focused on issues specific to that specialty (i.e. medicine, nursing, radiology). The purpose of this paper is to describe how an interdisciplinary team, led by nursing faculty within a college of health sciences (CHS), adapted to the changes driven by COVID-19 and the lessons that were learned; lessons that apply to multiple disciplines in higher education.

\section{Background}

The first case of coronavirus-19 (COVID-19) in the United States was confirmed on January 21, 2020 [31]. Although the virus spread quickly across the country, there were no confirmed cases in Delaware through February and the first week of March. Our academic institution monitored the situation closely and on March $10^{\text {th }}$ activated its Emergency Operations Center (EOC). Campus officials met daily to make real-time decisions related to the safety of the campus community. The President of the university announced that the campus was gearing up for online delivery of all courses if COVID-19 cases were confirmed in the state. Faculty were instructed to make plans to work remotely for a potentially protracted length of time. University sponsored travel to all international locations was prohibited for the remainder of the spring semester and all travel plans had to be registered with the university's Office of Risk Management.

The University set up a call center to address the coronavirus response. Members of the university community could contact the center for information on testing, who to contact if they were symptomatic, general questions about the virus, and the impact on university activities. Prior to this, the Information 
Technology (IT) staff had been working over the previous few years to standardize software on all university owned computers (Table 1). This preparation would prove to be critical to the success of the university community in adjusting to the sudden changes wrought by COVID-19.

On Wednesday March 11, 2020, the university received confirmation from the Delaware Division of Public Health that one person connected with the university had tested positive for COVID-19. Initially students could stay on campus and dining services were available to them. However, this changed the following day (March $12^{\text {th }}$ ) when three additional members of the university community tested positive for COVID-19. Field experiences in the CHS were cancelled, impacting students in all seven departments/schools/units. University owned and/or operated student housing facilities were closed, and students were required to leave campus by March $15^{\text {th }}$. Spring break was extended until March $29^{\text {th }}$ so that faculty could have additional time to convert all courses to an online format. Research on campus was restricted to only essential activities, mail services suspended, university buildings secured, and all in-person visits to university operated clinics (Nurse Managed Primary Care Center, Physical Therapy, Nutrition, Hearing and Speech Clinics) would close on March $19^{\text {th }}$, after which telehealth services would be provided.

The campus was essentially shut down between March $14^{\text {th }}$ and March $30^{\text {th }}$. During that time faculty were expected to transition all coursework to an online format. IT worked with faculty to help them optimize functional tools to foster the transition to distance learning. Multiple online modules were offered for users including Canvas LMS, Zoom, and PowerPoint slides with voiceover to foster synchronous (live) and asynchronous online learning.

As nursing faculty navigated the transition to an online teaching format, they began to contemplate the effects of this rapid change on their students and colleagues. Realizing that all departments within the college were affected by COVID-19, they invited others to share their insights. Multiple faculty expressed interest initially, but due to time constraints and other responsibilities, the interdisciplinary working group included representatives from nursing, medical and molecular sciences, physical therapy, and a $\mathrm{PhD}$ student in nursing. The group met weekly to discuss how COVID-19 affected their individual departments and

Table 1. Standardized software available to university faculty.

- VPN: Virtual Private Network

- Zoom (Video conference solution allowing remote collaboration as well as remote IT support if needed)

- 2Fa (2-Factor Authentication) (Provides a rolling 6-digit code as an added security measure to username/password)

- MFA (Microsoft 2-Factor Authentication)

- Cloud Storage/Collaboration Tools

- OneDrive (Online storage solution from the Office 365 suite of products)

- Google Drive (Online storage solution from Google Apps featuring unlimited space) 
discuss similarities, differences, and lessons they could share with their colleagues.

\section{Methods}

The interdisciplinary group met weekly via Zoom conferencing and created a comprehensive list which captured the impact wrought by COVID-19 on their academic disciplines. The catalog of experiences and outcomes was placed in an inclusive bucket list and then cross-referenced to each discipline. Collective review enhanced by the contextual experiences of each member resulted in multiple thematic categories. Further discussion led to the identification of four inclusive categories and several sub-categories. These were: academic considerations (didactic, lab, clinical), perceptions (faculty, student), ethical considerations, and social determinants affecting the learning environment (Table 2).

Academic considerations: This category identified mandated changes from the university about the provision of didactic and clinical education. Three subcategories (didactic, lab, and clinical), reflected specific issues related to technology, academic integrity, curriculum changes, students with diverse learning needs, communication, workload, emergencies, simulation, clinical impact, and transition to telehealth.

Perceptions: This category was divided into two sub-categories (faculty and student) and addressed perceptions of the abrupt changes brought on by COVID-19, including the impact on mental health, employment, learning environment, and workload.

Ethical considerations: Issues related to academic integrity, clinical experiences, student employment, and competency to enter practice were included in this category.

Social determinants affecting the learning environment: This classification highlighted the significant social impacts and the unique learning environment challenges experienced by both faculty and students.

Academic Considerations-Didactic: Some issues the work group encountered were reported by others around the country and across continents. In general, faculty were given short notice to transition from in-person or hybrid teaching to an entirely online format [5] [8] [14] [16] [17] [21].

The most immediate academic concern among university faculty was maintaining the quality academic standards to which students were accustomed, while transitioning to an online format [1] [16] [17] [21].

Table 2. Thematic categories and sub-categories cross referenced across disciplines.

\begin{tabular}{cc}
\hline Categories & Subcategories \\
\hline Academic Considerations & Didactic, Lab, Clinical \\
Perceptions & Faculty, Student \\
Ethical Considerations & \\
Social Determinants Affecting the Learning Environment &
\end{tabular}


A second major concern for CHS faculty was familiarizing themselves with the university LMS. Although faculty used the LMS to post course syllabi, schedules, and lecture materials, many were unfamiliar with the complexities of teaching entirely online. IT offered crash course online modules and one-on-one tutorial sessions to help faculty make this transition. The extent of CHS faculty experience with online teaching varied widely. Some had never taught an online course and others had provided multiple courses using a distance format. This discrepancy was reported by others [16] [17] [20] [28].

Many faculty experienced an uneven transition from classroom to online education. For example, faculty had to have access to a reliable internet connection. If they planned to teach online classes synchronously (live), they needed a webcam for visual and audio contact. The university had contracted to use Zoom video conferencing for online teaching and mastering this format required additional and rapid education for faculty by IT. Table 3 illustrates common issues related to the transition to online learning.

Once CHS faculty had attained a working knowledge of the LMS and were able to transition class content to an online format, other issues demanded their attention. Decisions had to be made about the best way to communicate with students, divide course content into manageable units, modify assignments, promote active learning, use of offline (self-learning) education, and assessment of student progress [5] [16]. Evaluation of students frequently involves written exams to gauge their progress. Faculty often monitor students in the classroom during exams, but how would they surveil student behavior during online exams? Several departments in the college purchased exam monitoring software that provided remote monitoring of students via their webcam. If a student displayed suspicious behavior (e.g. left the room, looked at notes), the faculty member would receive an electronic alert to evaluate the situation.

Some CHS faculty created alternative assignments (e.g. writing exercises, reflections, essay exams) on the LMS for evaluative purposes. Another consideration for faculty was how to accommodate students with disabilities, since the

Table 3. Issues in transitioning to online learning.

- Working computer

- Reliable internet access

- Adequate bandwidth for online classes

- Webcam

- Speakers

- Time-zone considerations for out of state/country students

- Netiquette

- Familiarity with the LMS

- Private (and interrupted) space to teach/hold class

- Manipulating Zoom conference functions (i.e. how to start, end, record, mute, show a video, closed capture, whiteboard, edit recordings, etc.)

- Benefits and drawbacks between synchronous and asynchronous teaching 
university closed the disability support services center designed to meet their needs. Some faculty worried that students with attention deficits might find Zoom conferencing distracting and that hearing-impaired students might be challenged if they could not see the faculty member and not be able to read lips, or ask questions in real time.

Faculty workload increased during the transition from campus-based to online education. The university faculty members are unionized and have specific parameters for workload. However, they were generally not concerned with workload as much as they were with creating meaningful learning experiences on a single platform (i.e. online). Alternative evaluation measures, grading, and feedback to students in the new online format added to faculty workload.

Communication during the transition to online learning (university and faculty, faculty and students, faculty and IT, faculty and clinical agencies) was near constant and carried out primarily via email. At times, it seemed that the communication evolved from conversation to cacophony [32]. Overloaded email accounts could result in a failure to read important announcements related to the university's response to COVID-19. Most CHS faculty adjusted by developing a priority scale that ranged from need to know, nice to know, and not important. To address the communication issue, the university created a COVID-19 web page to keep faculty, students, and staff informed of decisions that affected them. This approach reflected a report by Poonia and Raiasekaran who developed a one-page centralized document called a quicksheet to inform clinicians of changes in guidelines and policies [33]. However, communication continued at a mind-bending rate as faculty worked to transition classes to an online format.

\section{Academic Considerations-Lab/Clinical:}

As the pandemic spread in the region, clinical institutions affiliated with the CHS began to withdraw placements for students in the practice professions (e.g. nursing, physical therapy, medical laboratory science). Concurrently, the university administration mandated the discontinuation of outside placements for undergraduate students. Thus, undergraduates in all departments across the college were prohibited from participation in clinical rotations and simulated laboratory experiences both on and off-campus.

These decisions posed a serious challenge to the CHS faculty. Many health professions have strict requirements for clinical and laboratory hours to adequately prepare students for practice and/or licensure. For example, the board of nursing in our state requires that undergraduate nursing students complete at least 400 clinical hours before they can take the National Council Licensure Examination (NCLEX-RN). Medical laboratory science certification does not require a specific minimum number of clinical hours, but the program at our institution aims for at least 640 hours and an additional 20-hours practice in phlebotomy. The graduates from the department of physical therapy take the National Physical Therapy Examination (NPTE) after completing 30 full-time weeks of clinical hours. 
To address the matter of required clinical hours, undergraduate courses in nursing, medical laboratory science, dietetics and other programs in the college were converted to online practicum experiences. This presented unique challenges regarding resources, simulating real-world activities online, assessing psychomotor skills, and providing comparable experiences to match course credits. Many of the psychomotor skills that CHS students must practice, master, and demonstrate require specialized equipment or partners/patients that students could not access from their homes during the pandemic. Franchi discussed this issue regarding students in anatomy classes [34]. He noted that online education did not compensate for the limited access to models, pathology specimens, and application of dissection skills. Simulations for some clinical experiences were available online and shared across disciplines within the CHS. For example, the university paid for and provided access to Assessment Technology Institute (ATI), to provide a virtual simulation called V-Sim Real Life scenarios. This helped provide adult, mental health, pediatric, and maternal health scenarios to replace in-person clinical experiences. For those skills that did not have readily available online resources, faculty developed video-based demonstrations when possible. However, lack of faculty access to their CHS laboratories and offices made this an ongoing challenge.

COVID-19 prompted the Commission on Accreditation in Physical Therapy (CAPTE) to modify clinical hours to include telehealth, e-visits, virtual check-ins, remote evaluation of recorded video or images, and telephone assessment and management services as acceptable alternatives. Similar accommodations were allowed in nursing, medical and molecular sciences, and other disciplines within the college. Although telehealth provided students with somewhat comparable interactive experiences, they missed the hands-on or F2F patient encounters [14] [34]. Conversely, graduate students who were able to engage in F2F clinical experiences faced possible exposure to COVID-19. Some facilities utilized by the CHS provided sufficient personal protective equipment (PPE) while others had an insufficient supply or required the university to supply PPE for the students (e.g. gloves, masks, gowns).

Perceptions: This category was subdivided into faculty and student perceptions, each presenting with similar, yet unique experiences related to the impact of COVID-19. Faculty in the CHS perceived a significant increase in workload and sudden curriculum changes. They were expected to redesign course delivery methods and create new online assessments to evaluate student learning outcomes [16] [20] [21] [30]. Students reported an increase in workload due to additional projects and papers, altered timelines, and COVID-19 crash course modules mandated by the university. They anticipated that CHS faculty would be ready to teach in an online format. This mind set was corroborated by Jowsey and colleagues who reported that students expected faculty to be competent with technology, keep the infrastructure functioning, and address technical issues when they arose [30]. For CHS students, the learning environment was extremely challenging, as there was a blurring of lines between home and school, 
family interruptions and expectations, lack of privacy, and limited quiet spaces in which to study. Some communication strategies initiated by faculty to decrease student stress included online discussion boards, forums, and Zoom conferencing [30] [35].

Senior students across disciplines in the college conveyed increased levels of anxiety related to employment post-graduation. Nursing students reported that residency programs to which they applied were put on hold, while others were unable to schedule job interviews. Another concern for the senior nursing students was related to the NCLEX-RN. They worried that the absence of their final clinical experience/preceptorship would negatively affect their practice competency and scores on the exam. To address this concern, ATI (V-Sim Real Life scenarios) was implemented to assist the students with critical thinking and facilitate their confidence and competence level before they took the exam.

Due to COVID-19, the university changed traditional plus/minus grading for the semester, adding a modified pass/fail option for students. Those who were considering enrollment in master's or PhD programs expressed concern about how the modified grading criteria might affect their applications [10] [21] [30] [35]. Both faculty and students in the CHS described mental health issues that were prompted by the change from F2F classes to a fully online format. Stress, isolation, lack of support, and shortened timelines were some of the concerns that faculty shared; whereas students expressed fear, anxiety, isolation, lack of supportive relationships, grief related to the loss of what was, and the desire for increased empathy from faculty [3] [7] [30] [35]. Both groups expressed unease about altered evaluation criteria, additional assignments, and attention to both formative and summative learning, which was reported by others [3] [7] [30] [35].

Ethical Considerations: When the abrupt move to online instruction occurred in March of 2020, there were uncertainties about academic integrity, the impact on the availability and quality of clinical experiences for the CHS students, readiness to enter practice, and COVID-driven consequences on employment opportunities for graduates. Proctoring methods using webcam monitoring of student assessments was financially supported by the University, but quickly became difficult to acquire because of overwhelming requests from across the country. Delays in recruiting proctors meant extending the time frame for students to complete online assessments. A few students objected to the live proctors watching them via webcams, citing uncomfortable experiences and additional anxiety. Alternatively, some CHS faculty adopted live Zoom proctoring of students, which worked with small groups of students, but not as well with large classes.

To resolve these issues, several faculty in the school of nursing, laboratory coordinators and faculty in medical and molecular sciences opted to give open-book assessments, which may have led to grade inflation. Faculty reduced the time for completion of examinations, prevented backward navigation, and added higher level questions to promote academic honesty. Recent recommendations from the university Center for Teaching and the Assessment of Learning 
(CTAL) promoted the design and use of authentic assessments in place of traditional written examinations. Authentic assessments connect to real-world issues and allow the students to apply their skills and knowledge to scenarios they may face in the future (for example asking students to synthesize information and/or use critical-thinking skills) [36].

Providing real world experiences for CHS students was challenging because some affiliated institutions reduced the length of student placements, while others limited the number of students to maintain COVID-19 restrictions. This created ethical concerns for faculty because students required experience in various clinical areas to achieve clinical competence. For example, nursing students needed exposure to geriatric patients, but due to the higher risk of COVID-19 with this age group, experiences were limited. Physical therapy graduate students expressed concerns about placements in geographic locations with higher COVID-19 rates of infection. Faculty wondered if it was ethical to send some students to these areas, while others were placed in an affiliated institution that had a much lower rate of infection. Others around the globe also expressed concerns about being exposed to COVID-19 on campus and during clinical experiences. Their concern extended to others with whom they shared physical space [12] [20].

Many healthcare institutions utilized by the CHS had furloughs in place, yet students needed clinical placements. Was it ethical to request a student placement when clinical staff were furloughed? Students who graduated in May of 2020 and who experienced abbreviated, virtual practicums have moved into practice as healthcare professionals. As a result, they missed hands-on patient contact, assessments, and interpersonal skills that they would normally have practiced. Faculty were apprehensive about potential ethical implications regarding student readiness to practice given the change in clinical experiences caused by COVID-19.

Graduates in the spring of 2020, who sought employment, had varying degrees of success in securing entry-level positions in their respective fields. Elective surgical procedures and other non-emergent services were suspended for a time, creating financial losses for the institutions, and hiring freezes. Outpatient physical therapy clinics experienced significant reductions in clientele appointments. A persistent dilemma faced by CHS faculty during the pandemic was how to advance currently matriculated students toward future careers and continue to admit new students while employment opportunities were tenuous. In the clinical laboratory, the increased demand for molecular testing for the SARS-CoV-2 virus necessitated the reallocation of staff toward this area of testing, while other areas of the clinical laboratory experienced decreased workload. Despite these challenges, $92 \%$ of the medical laboratory science 2020 graduates in the CHS obtained employment within two months of graduation. Employment for nursing graduates was sometimes delayed because of COVID-19 restrictions on test sites to take the NCLEX-RN exam. For example, May, 2020 
graduates could not be scheduled to take the exam until August or September. Before COVID-19, May graduates could take the exam as early as June.

\section{Social Determinants}

At universities across the nation, the social landscape of learning for health professions students and educators changed in profound ways as they adapted to an online format. The sub textual impacts of social disparities became glaringly evident for many students who returned home to find learning environments unsuited for academic progress and success [13] [20] [21].

Students in the CHS experienced drastic disruptions from the normal and routine stability provided by university classrooms, peer support, dormitory settings, and cafeteria meals. When the university campus was closed some students were left in precarious situations [21], often in spaces that did not allow for physical distancing [13]. Ready access to the internet was sometimes not available where multiple users and limited speed impacted student productivity. Students experienced competing responsibilities in continuing their education virtually. These included family obligations such as taking care of younger siblings or a return to work to help supplement the family income impacted by COVID-19 furloughs and lay-offs.

Social stressors for our students included negative feedback from parents, spouses, loved ones and friends regarding the value of an education that transitioned from a F2F to an online format. Several reports noted a dissatisfaction with a perceived benefit to cost loss when moving from F2F to online education [12] [21]. Lack of access to laboratory exercises, supplementary services and clinical experiences resulted in the students questioning what the long-term impact would be on their future success [12] [13] [19] [20].

Our faculty and administration actively worked to address the perceived isolation and segmentation of the student body and provided opportunities for building support and outlets for communication. The university established a central website for the dissemination of information on COVID-19 recognition, testing, social distancing, and new policies and processes with a direct link to the university home page (https://www.udel.edu/home/coronavirus/). The COVID-19 website serves as a hub to link caregivers, academics, students, families, and the local community together as united and informed. The Protect the Flock campaign at the university provides reminders for health checks, schedules for COVID-19 testing, health and hygiene practices, the latest developments in vaccine development and state by state health. More importantly, it provides a shared space for all who may feel isolated, forgotten, or fearful to connect with another.

\section{Lessons Learned}

This project was innovative in that an interdisciplinary group worked together for the purpose of identifying the impact of COVID-19 on both students and fa- 
culty in the college. Most previous publications related to the effect of COVID-19 focused on a single profession (e.g. medicine, nursing, radiology), that lacked the perspective provided by a broader interdisciplinary view. This collaboration helped us to discover commonalities across disciplines that included the importance of communication, providing support to all stakeholders, maintaining connections with clinical partners, addressing safety concerns related to the pandemic, and managing stress. Communication is integral to help students and faculty successfully navigate the uncertainty of rapid disruptions in curricular instruction due to COVID-19. Faculty must plan carefully to ensure continuity in instruction and access to resources and support. Students need consistent communication from their instructors, and clear descriptions of any changes in grading policies and assessments. Changes in or loss of traditional hands-on clinical instruction in each discipline must be clearly articulated and alternatives made available so that students can meet the accreditation standards required in their field of study.

Our interdisciplinary approach taught us that a balance between synchronous and asynchronous instruction is essential. There must be ongoing opportunities for students to interact with faculty and their peers. Students need to know that faculty are fully invested in their success, particularly when instruction is online. In the healthcare practice professions, it is critically important to maintain connections with clinical partners and to utilize their expertise in novel ways to enhance virtual and actual experiences for the students. Engagement with clinical partners is essential even as they face their own challenges related to the pandemic. As students participate in clinical practicums during the pandemic, they should be prepared for ongoing screening and safety measures required for personal and patient safety. Stressors imposed by the pandemic underscore the importance of having academic and psychological support systems available for students, faculty, and staff.

\section{Conclusion}

The CHS interdisciplinary workgroup was composed of faculty from different departments in the CHS. We had common concerns and perceptions as the university transitioned from an on-campus F2F teaching-learning environment to an online format in an extremely short time frame. Faculty across disciplines benefitted by working together and learned from each other how to meet the challenges of teaching during the COVID-19 pandemic. Nursing and other health-related disciplines should pursue interdisciplinary collaboration to address common issues that arise during the COVID pandemic and in the future.

\section{Acknowledgements}

The CHS workgroup acknowledges the contributions of Ellen Wruble, PT, SCcPH, MS, Director, Doctorate in Physical Therapy Program at the University of Delaware, Department of Physical Therapy. Her insights and thoughtful sug- 
gestions were valuable contributions to this project.

\section{Conflicts of Interest}

The authors declare no conflicts of interest regarding the publication of this paper.

\section{References}

[1] Abbasi, S., et al. (2020) Perceptions of Students Regarding E-Learning during Covid-19 at a Private Medical College. Pakistan Journal of Medical Science, 36, S57-S61. https://doi.org/10.12669/pjms.36.COVID19-S4.2766

[2] Almarzooq, Z., Lopes, M. and Kochar, A. (2020) Virtual Learning during the COVID-19 Pandemic. Journal of the American College of Cardiology, 75, 2635-2638. https://doi.org/10.1016/j.jacc.2020.04.015

[3] Cao, W., et al. (2020) The Psychological Impact of the COVID-19 Epidemic on College Students in China. Psychiatry Research, 287, Article ID: 112934. https://doi.org/10.1016/j.psychres.2020.112934

[4] Kogan, M., et al. (2020) Orthopaedic Education during the COVID-19 Pandemic. Journal of the American Academy of Orthopaedic Surgeons, 28, e456-e464. https://doi.org/10.5435/JAAOS-D-20-00292

[5] Singh, K., et al. (2020) Medical Education during the DOCID-19 Pandemic: A Single Institution Experience. Indian Pediatrics, 57, 678-679. https://doi.org/10.1007/s13312-020-1899-2

[6] Weiss, P. and Li, S.-T.T. (2020) Leading Change to Address the Needs and Well-Being of Trainees during the COVID-19 Pandemic. Academic Pediatrics, 20, 735-741. https://doi.org/10.1016/j.acap.2020.06.001

[7] Barabari, P. and Moharamzadeh, K. (2020) Novel Coronavirus (COVID-19) and Dentistry-A Comprehensive Review of Literature. Dentistry Journal, 8, 53. https://doi.org/10.3390/dj8020053

[8] Elangovan, S., Mahrous, A. and Marchini, L. (2020) Disruptions during a Pandemic: Gaps Identified and Lessons Learned. Journal of Dental Education, 84, 1270-1274. https://doi.org/10.1002/jdd.12236

[9] Iver, P., Aziz, K. and Ojcius, D. (2020) Impact of COVID-19 on Dental Education in the United States. Journal of Dental Education, 84, 718-22. https://doi.org/10.1002/jdd.12163

[10] (2020) World Physiotherapy Response to COVID-19, Briefing Paper 3. https://world.physio/sites/default/files/2020-07/Education-Briefing-paper-3-Student s-24-June-2020.pdf

[11] Bogossian, F., McKenna, L. and Levett-Jones, T. (2020) Mobilising the Nursing Student Workforce in COVID-19: The Value Proposition. Collegian, 27, 147-149. https://doi.org/10.1016/j.colegn.2020.04.004

[12] Collado-Boira, E., et al. (2020) “The COVID-19 Outbreak"-An Empirical Phenomenological Study on Perceptions and psychosocial Considerations Surrounding the Immediate Incorporation of Final-Year Spanish Nursing and Medical Students into the Health System. Nurse Education Today, 92, 1-5. https://doi.org/10.1016/j.nedt.2020.104504

[13] Dewart, G., et al. (2020) Nursing Education in a Pandemic: Academic Challenges in Response to COVID-19. Nurse Education Today, 92, Article ID: 104471. 
https://doi.org/10.1016/j.nedt.2020.104471

[14] Morin, K. (2020) Nursing Education after COVID-19: Same or Different? Journal of Clinical Nursing, 29, 17-18. https://doi.org/10.1111/jocn.15322

[15] Savitsky, B., et al. (2020) Anxiety and Coping Strategies among Nursing Students during the COVID-19 Pandemic. Nurse Education in Practice, 46, Article ID: 102809. https://doi.org/10.1016/j.nepr.2020.102809

[16] Bao, W. (2020) COVID-19 and Online Teaching in Higher Education: A Case Study of Peking University. Human Behavior, and Emerging Technologies, 2, 113-115. https://doi.org/10.1002/hbe2.191

[17] Daniel, J. (2020) Education and the COVID-19 Pandemic. PROSPECTS, 49, 91-96. https://doi.org/10.1007/s11125-020-09464-3

[18] Huckins, J., et al. (2020) Mental Health and Behavior of College Students during the Early Phases of the COVID-19 Pandemic: Longitudinal Smartphone and Ecological Momentary Assessment Study. Journal of Medical Internet Research, 22, 1-13. https://doi.org/10.2196/20185

[19] Redden, E. (2020) Clinical Education in a Pandemic Era. Inside Higher Ed.

[20] Seymour-Walsh, A., et al. (2020) Adapting to a New Reality: COVID-19 Coronavirus and Online Education in the Health Professions. Rural and Remote Health, 20, Article ID: 6000. https://doi.org/10.22605/RRH6000

[21] Supiano, B. (2020) Pandemic Pedagogy and the Limits of Compassion. The Chronicle of Higher Education.

[22] Pambuccian, S. (2020) The COVID-19 Pandemic: Implications for the Cytology laboratory. Journal of the American Society of Cytopathology, 9, 202-211. https://doi.org/10.1016/j.jasc.2020.03.001

[23] Pütz, G., Müller, M. and Winkler, K. (2020) A Cohort-Based Emergency Plan to Maintain Functionality in a Clinical Laboratory during the 2020 COVID-19 Epidemic Outbreak. Journal of Laboratory Medicine, 44, 113-115.

[24] Dean, E., et al. (2020) Translating COVID-19 Evidence to Maximize Physical Therapists' Impact and Public Health Response. Physical Therapy, 100, 1458-1464. https://doi.org/10.1093/ptj/pzaa115

[25] Gagnon, K., et al. (2020) Doctor of Physical Therapy Education in a Hybrid Learning Environment: Reimagining the Possibilities and Navigating a "New Normal". Physical Therapy, 100, 1268-1277. https://doi.org/10.1093/ptj/pzaa096

[26] Lee, A. (2020) COVID-19 and the Advancement of Digital Physical Therapist Practice and Telehealth. Physical Therapy, 100, 1054-1057.

https://doi.org/10.1093/ptj/pzaa096

[27] Alvin, M., et al. (2020) The Impact of COVID-19 on Radiology Trainees. Radiology, 296, 246-248. https://doi.org/10.1148/radiol.2020201222

[28] Slanetz, P., et al. (2020) Coronavirus Disease 2019 (COVID-19) and Radiology Education-Strategies for Survival. Journal of the American College of Radiology, 17, 743-745. https://doi.org/10.1016/j.jacr.2020.03.034

[29] Virarkar, M., et al. (2020) Radiology Education amid COVID-19 Pandemic and Possible Solutions. Journal of Computer Assisted Tomography, 44, 472-478. https://doi.org/10.1097/RCT.0000000000001061

[30] Jowsey, T., et al. (2020) Blended Learning via Distance in Pre-Registration Nursing Education: A Scoping Review. Nurse Education in Practice, 44, Article ID: 102775. https://doi.org/10.1016/j.nepr.2020.102775

[31] McNamara, A. (2020) CDC Confirms First Case of Coronavirus in the United States. 
https://www.cbsnews.com/news/coronavirus-centers-for-disease-control-first-caseunited-states/

[32] Nematzadeh, A., et al. (2019) Information Overload in Group Communication: From Conversation to Cacophony in the Twitch Chat. Royal Society Open Science, 6, Article ID: 191412. https://doi.org/10.1098/rsos.191412

[33] Poonia, S. and Raiasekaran, K. (2020) Information Overload: A Method to Share Updates among Frontline Staff during the COVID-19 Pandemic. Otolaryngology-Head and Neck Surgery, 163, 60-62. https://doi.org/10.1177/0194599820922988

[34] Franchi, T. (2020) The Impact of the Covid-19 Pandemic on Current Anatomy Education and Future Careers: A Student's Perspective. Anatomical Sciences Education, 13, 309-312. https://doi.org/10.1002/ase.1966

[35] Sahu, P. (2020) Closure of Universities due to Coronavirus Disease 2019 (COVID-19): Impact on Education and Mental Health of Students and Academic Staff. Cureus, 12, e7541. https://doi.org/10.7759/cureus.7541

[36] Gulikers, J., Bastiaens, T. and Kirschner, P. (2003) A Five-Demensional Framework for Authentic Assessment. Technology Research \& Development, 52, 67-85.

https://doi.org/10.1007/BF02504676 